\title{
QORPO SANTO - A LOUCURA CRIADORA
}

\author{
Maria Cristina de Souza
}

José Joaquim de Campos Leão, Qorpo Santo, parece ser a figura mais controvertida da dramaturgia nacional. Sua obra ora é apontada como produto de uma mente inferior perturbada pela doença mental, ora como produto de uma mente genial que não é compreendida.

Entre as duas opiniões fica-se com nenhuma, ou antes, com ambas. Isto significa dizer que o que se pretende é ver em Qorpo Santo uma mente genial que se mascara através da loucura.

O teatro de Qorpo Santo, cada uma de suas personagens, além de surgir como um dos veículos de sua vingança contra o meio social e os desajustes humanos, é a expressão da criação artística em seu mais alto grau de elaboração, sobretudo as peças: "As Relações Naturais"; "Hoje sou um; e Amanhã outro"; "A Impossibilidade da Santificação; ou a santificação transformada" e "Lanterna de Fogo"(1).

\section{A máscara}

Sabe-se que a sociedade impõe ao indivíduo diversas diretrizes e normas que estabelecem um padrão social, cuja existência é necessária para que não se caia na caoticidade. Porém, tal forma fixa de vida, por vezes, acaba estrangulando e sufocando por completo o movimento natural da existência humana. Viver então torna-se dissimular, e o homem, uma marionete comandada pelas regras e princípios sociais.

Comumente, vestir uma máscara é a maneira que o sujeito encontra para não entrar em conflito com a sociedade.

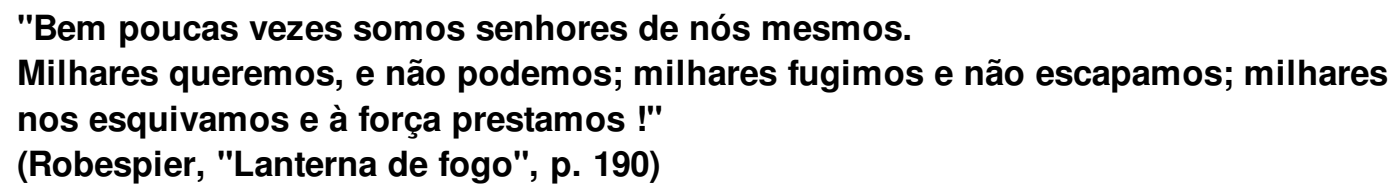

"Bem poucas vezes somos senhores de nós mesmos. Milhares queremos, e não podemos; milhares fugimos e não escapamos; milhares nos esquivamos e à força prestamos !" (Robespier, "Lanterna de fogo", p. 190)

"Para sair-se bem; é preciso só fazer o que mais convém." (Robespier, "Lanterna de Fogo", p. 196)

A máscara de marginal não é escolhida pelo próprio indivíduo. É atribuída pela sociedade àqueles que não aceitam se submeter ou se adaptar a ela. De modo especial, a máscara de louco é um instrumento indispensável para a manutenção do status quo social, sobretudo da instituição familiar.

Existe a discórdia conjugal. Mas, sendo o matrimônio sagrado e indissolúvel, a solução apresentada pelo divórcio é considerada escandalosa e inaceitável, enquanto a doença mental de um dos cônjuges e seu tratamento hospitalar, preferencialmente com reclusão, são vistos como uma bênção.

A atribuição da máscara da loucura é um gesto que tem significado político, moral, religioso, econômico e social, é o meio que "permite ao grupo eliminar os elementos que lhe são heterogêneos ou nocivos" (2).

Segundo Michel Foucault, a família como núcleo social é o critério essencial, é quem define, regimenta, exclui, facilmente, tudo o que lhe não convém, considerando loucura. Esta é posta à disposição da família burguesa que, de certo modo, passa a tirar proveito dela.

Qorpo Santo, na autobiografia que pertence às páginas da "Enciclopédia, ou seis meses de uma enfermidade", revela o prestígio que possuía no ministério público, e faz referência a "atos violentos" contra sua pessoa. Contudo, não deixa claro a origem ou a espécie de tais atos. É através de documentos reunidos em "A Saúde e a Justiça" que se vem a saber de exames de sanidade mental aos quais teve de se submeter, sem que os antecedentes para a realização dos referidos exames fossem esclarecidos de maneira satisfatória. 
Pelo contrário, como o próprio dramaturgo diz em ofício enviado ao escrivão de órfãos, os exames se apresentam como crimes horrorosos, "sempre com pretextos frívolos"(3).

Somente na explicação que antecede as falas da peça "A Impossibilidade de Santificação// ou a Santificação Transformada" Qorpo Santo relata o conflito doméstico de que se vê vítima, o qual, possível e provavelmente, tenha sido o responsável pela aquisição da máscara de louco.

"Existia em certa cidade da província de São Pedro do Sul um homem, cuja vida desde a infância foi digna do maior respeito e atenção. (. . .) Casado na idade de 27 anos, com uma moça de 22, (. . .) Se, porém, deixaram de lutar com as crianças, nem por isso mesmo deixaram de o fazer consigo mesmos com outros indivíduos. Tornaram-se em vez de maiores amigos do que dantes eram, os mais encarniçados inimigos. (. . .) A mais encarniçada luta se travou entre esta $e$ aquele: tudo quando o marido pedia-Ihe era negado; dado ou apresentado justamente o contrário do que ele desejava. (. . .)"

(Explicação. "A Impossibilidade da Santificação; ou a Santificação Transformada", p. 295)

Por repetidas vezes, os laudos médicos consideraram Qorpo Santo apto para gerir seus bens, gozando de plena saúde mental, apresentando apenas um acréscimo de atividade cerebral, uma vivacidade e atividade maior do pensamento.

"Com efeito! Até do meu estômago saem pensamentos!"

(Robespier, "Lanterna de Fogo", p.200)

Entretanto, os últimos laudos já não são unânimes e acabam levando Qorpo Santo a ser interdito pela Justiça. Parecendo que a insistência com que a família tenta fazer de Qorpo Santo um demente, acaba tendo seus frutos.

Ao se considerar a peça "Hoje sou um; e Amanhã Outro" percebe-se que o reino ali existente é uma metáfora para a sociedade na qual vivia Qorpo Santo.

O reino sofre o perigo de uma rebelião interna e de uma invasão estrangeira. A sociedade do século XIX, por sua vez, sofre os perigos da insubmissão de um de seus membros e da mudança dos estatutos que servem de base a ela. Desta forma, a invasão estrangeira e a rebelião interna, na realidade partes de uma mesma e única revolta, têm de ser dissipadas . O Rei e a Rainha são os representantes da ordem dominante, enquanto Qorpo Santo encaixa-se perfeitamente na figura do inimigo. Embora combatesse a sociedade, o autor fazia parte dela, por isso identifica-se com o ministro que aparece na peça, o porta-voz de uma nova sabedoria.

Não importa ao Rei e à Rainha o que venha a acontecer com o povo do reino, pois o primeiro objetivo é vencer o inimigo; sabem que a luta fará o povo sofrer, mas

"quando a Pátria periga! Quando o inimigo audaz se atreve a insultá-la; quando tudo pode gemer; se o Rei franquear; não deve ele reflexionar sobre as conseqüências; tem uma única revolução a tomar".

(Rei, "Hoje sou um; e Amanhã Outro". p.114)

É assim que, Rei e Rainha ao acabar com os revoltosos, conseguem vivier felizes e tranqüilos,embora estivessem

"os mares repletos de cabeças, de corpos que boiavam dso nossos inimigos, como se uma peste houvesse destruído a vida de milhares de peixes". (Rainha."Hoje sou um ..., p.118)

Vendo-se impossibilitado de provar, em definitivo, sua sanidade, Qorpo Santo toma para si o papel de louco para não mais o largar. Afinal, "o direito há muito que é morto". (Impertinente, "As Relações Naturais", p.70)

O dramaturgo reconhece os limites de sua resistência, percebe que apenas por algum tempo é possível lutar contra a sociedade, uma vez que "sempre a Lei, a Razão e a Justiça triunfam da perfídia, da traição e da maldade", conforme explicam o rei e a Rainha ao final da comédia "Hoje sou um ; e Amanhã Outro". (p.120) 
É ironicamente que Qorpo Santo admite a teoria de que "se é impossível deixar de representar um papel, então a única alternativa é interpretar o papel até os seus limites extremos"(4).

\title{
O teatro
}

O teatro nasce e tem seu fundamento na máscara; ao mesmo tempo que a põe, retira-a. Quando o homem representa ser outro, coloca a máscara deste outro e tira sua própria máscara, revelando-se por inteiro. Como afirma Mead, "o homem tem de "sair" de si para chegar a si mesmo"(5)

O teatro visa à libertação do homem. O mito do teatro como meio de se alcançar a verdade do sujeito, a liberdade do gênero humano, remonta à lenda hindu em que o teatro tem origem na comemoração da vitória do deus Indra sobre os demônios. Esta lenda mostra claramente a essência do drama como luta libertadora colocando em cena os demônios aprisionadores do homem, que têm de ser exorcizados para que este fique livre.

O nascimento do teatro tem sua justificativa na necessidade do homem de fugir de seus demônios, e se evadir de uma sensação difusa e profunda de perigo, diante do qual é impotente e por isso se sente oprimido. $O$ teatro torna 0 irreal mais verdadeiro que o real.

\begin{abstract}
"Faz de nossos mais vagos sonhos, de nossas mais difusas aspirações, de nossas mais inconscientes necessidades, não mais testemunhos de impotência ou de fugas estéreis, mas um trampolim para uma Humanidade mais lúcida e mais violentamente ávida de sua própria realização" (6)
\end{abstract}

O teatro chamado de "Teatro de Protesto" encontra sua base ideológica no inconformismo do indivíduo diante da situação de impotência. É o teatro que envolve o dramaturgo explorando sua própria personalidade, como idéia ou personagem. É o teatro que envolve o dramaturgo explorando sua própria personalidade, como idéia ou personagem. É assim, que, na peça "A Impossibilidade da Santificação; ou a Santificação Transformada", Qorpo Santo aparece como C-s, personagem que tem por nome as suas iniciais na ortografia corrente.

Qorpo Santo, enquanto dramaturgo e louco, encontra chance de flagrar suas denúncias. Sua revolta não se conduz em uma única direção, o que faz de seu teatro um revisor das relações entre Deus e o homem, o homem e a comunidade, e do homem consigo mesmo.

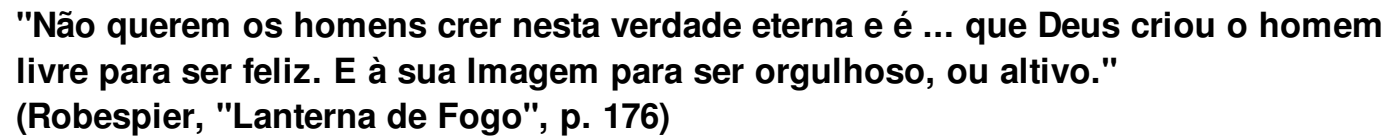

"E quanto mais chegam à impostura chamada - Religião, mais apaixonados são do tal melão ..."

(Simplício, "Lanterna de Fogo", p. 180)

"São hoje 14 de maio de 1866. Vivo na cidade de Porto Alegre, capital da Província de S. Pedro do Sul; e para muitos, - Império do Brasil ... Já se vê pois que é isto uma verdadeira comédia". (Impertinente, "As Relações Naturais", p. 67)

O drama tem por convenção primordial o diálogo, o discurso fragmentado que possibilita o surgimento de contradições e antagonismos. O diálogo na dramaturgia de Qorpo Santo opera-se em dois níveis. Há o diálogo entre dois seres distintos, e há o diálogo entre as faces do mesmo ser, isto é, entre o "eu social", exterior, e o "eu individual", interior. O "eu social" é o que veste a máscara, o "eu individual" é o que se revela quando esta é retirada.

Qorpo Santo é um ser dividido entre o que a sociedade dita como certo e o que ele próprio assim o considera.

A noção da divisão do ser nasce com Freud e as teorias do consciente e do inconsciente. O homem deixa de ser uma unidade e passa a ser a união de fragmentos, que, por vezes, completam-se, por outras, opõem-se. 
Lacan, de acordo com a teoria freudiana do ser fendido, identifica dois sujeitos essenciais, ou fragmentos de ser. Um, o que anteriormente se denominou "eu social", ao qual Lacan chama de sujeito do inconsciente, do significante, da enunciação; é o sujeito "eu sou" (7).

O sujeito "eu falo" não revela o "sujeito "eu sou", pelo contrário, oculta-o.

\title{
"É preciso dizer-Ihe o contrário do que penso!" \\ (Impertinente, "As relações naturais", p. 68)
}

A máscara atribuída ao sujeito do enunciado faz com que ele não corresponda ao sujeito da enunciação. "O ator ao se disfarçar, revela a essência do homem" (8)

\section{A loucura}

Quando o "eu falo" torna-se totalmente independente do "eu sou", tem-se uma fragmentação doentia do ser, tem-se um caso de esquizofrenia. A loucura deixa de ser personagem e se torna real.

O sujeito esquizofrênico é aquele para o qual o sujeito do enunciado e o sujeito da enunciação perderam todos os liames, quaisquer pontos de contato. Ocorre uma ruptura no relacionamento do indivíduo com o mundo e na relação consigo mesmo.

Nestas condições, o ser se sente mais irreal do que real, mais morto do que vivo, parece ter uma personalidade que não é a sua. "O esquizofrênico ou não sabe quem e o que é, ou tornou-se algo ou alguém que não é ele próprio" (9). É um indivíduo que procura a solidão e o isolamento porque não se sente completo, mas dividido, talvez como uma mente ligada ao corpo por tênue fio, como duas personalidades, etc" (10)

No caso de Qorpo Santo, a esquizofrenia ou divisão do ser fica bem explicitada na atitude do dramaturgo em que declara que José Joaquim de Campos Leão subiu aos céus e em seu corpo surge Qorpo Santo. José Joaquim é o "eu falo" que morre para dar lugar ao "eu sou", Qorpo Santo.

O esquizofrênico é um ser sem esperanças, sente-se sem a assistência do Bem e do Mal, pois ele é o próprio Deus ou o Demônio.

\author{
"Poderiamos obter um retrato desse ente a meu ver tão grande ou maior que o \\ próprio Jesus Cristo!?" \\ (Rei, "Hoje sou um; e Amanhã Outro", p. 111)
}

"De ordem de Nosso Monarca, tenho a determinar a V.Sa. que no primeiro correio envie a esta corte um retrato do Dr. Q... S..., do maior tamanho, e mais perfeito que houver ..."

(Ministro, "Hoje sou um; e Amanhã Outro", p. 111)

A linguagem do esquizofrênico encontra força de expressão, principalmente através das palavras assassinato e fogo. A imagem do fogo é um correspondente para as flutuações de vida interior do indivíduo, assim como a imagem do assassinato se liga à morte da unidade do ser, com a sua fragmentação.

\section{"Incêndio! Incêndio! Incêndio! Venham bombas! Venha água! (É um labirinto, que ninguém se entende, mas o fogo, a fumaça que se observa, não passa, ou o incêndio não real, mas aparente)."} (Rubricas - "As Relações Naturais", p. 81)

A linguagem de Qorpo Santo, como a de todo esquizofrênico, é incoerente e nebulosa, parece não ter lógica, pois é uma linguagem baseada na sintaxe do inconsciente, análoga à linguagem onírica.

O sonho é a formação do inconsciente que mais se aproxima da loucura, a ponto do sonho ser considerado "a loucura do indivíduo adormecido" e os loucos "os sonhadores acordados" (11). Desta forma, o sonho é um acontecimento que permite compreeender a loucura. 
O sonho possui conexões absurdas, até mesmo contraditórias, do ponto de vista da coerência lógica. É uma atividade mental que possui sintaxe particular. Esta baseia-se em quatro princípios: a condensação, o deslocamento, a figuração e a elaboração secundária.

Na condensação, o conteúdo manifesto é menor que o conteúdo latente, ou porque se omitem elementos, ou porque se combinam vários elementos, ou porque se combinam vários elementos que possuem algo em comum em um único elemento.

Com o deslocamento, o conteúdo manifesto ou é uma alusão ao conteúdo latente, ou tem o acento feito em um elemento sem importância para ocultar o elemento fundamental.

A figuração é a seleção e transformação das idéias do sonho em imagens, enquanto a elaboração secundária é a responsável pela apresentação do sonho através de uma história coerente e compreensível.

O s princípios da condensação e do deslocamento fazem do sonho uma mensagem cifrada. Lacan identifica a condensação ao processo lingüístico da metonímia, e o deslocamento, à metáfora.

A dificuldade de compreensão de uma mensagem de um indivíduo esquizofrênico reside justamente neste ponto. É uma mensagem que tem como fundamentos básicos a metonímia e a metáfora.

Qorpo Santo na peça "Lanterna de Fogo" parece perceber a semelhança entre loucura e sonho, e celebrar o fato de que como louco é um eterno sonhador.

"Finalmente! Finalmente, é nunca acabar de sonhar!

Não parece que és homem; mas sim um sonho!"

(Zeferino, "Lanterna de Fogo", p. 175)

Nesta fala de Zeferino a Robespier, tem-se a impressão de que Qorpo Santo encontra em Robespier uma imagem espelhada, e que ao defini-lo, define também a si próprio.

Segundo Freud, a divisão do ser ocorre porque o homem é regido por dois princípios concorrentes: um, o princípio do prazer, o outro, da realidade. O louco é o indivíduo que se esquece do princípio da realidade e se deixa levar inteiramente pelo princípio do prazer, quando então sonho e loucura confundem-se novamente.

O principio do prazer somente é superado pelo da realidade quando este encontra na sociedade seu meio de projeção e preservação.

A fantasia, processo primeiro da loucura, é a única atividade mental que se conserva, de forma completa, fora do domínio do princípio da realidade. Como tal, a fantasia é o processo mental da liberação da repressão, compara-se ao desejo satisfeito. É uma ameaça à sociedade, já que o homem em comunidade deve censurar todas as manifestções do princípio do prazer. Portanto, o único modo possível para qualificar uma imaginação fértil, fruto da fantasia, é o pejorativo.

"... e já que a minha ingrata e nojenta imaginação tirou-me um jantar..." (Impertinente, "As relações naturais", p. 67)

Para a sociedade, o importante é o triunfo da razão em detrimento da imaginação. Assim, as verdades que a fantasia veicula precisam de outro espaço, para se apresentarem. A fantasia cria um universo de percepção e compreensão próprios, ganha forma por intermédio da arte.

Esta é, portanto, o espaço do "eterno protesto contra a organização da vida pela lógica da dominação" (12).

O louco e o artista se aproximam, são eles os seres que que deixam vir à tona as verdades da imaginação. Entre eles se estabelecem a mesma espécie de relação existente entre o sonho e a loucura; a arte é a loucura consciente, e a loucura, a arte do inconsciente.

A máscara social do louco ou marginal é a que se presta à mesma função que a máscara teatral. Qorpo Santo funde a máscara de artista e a de louco em uma só. A obra de Qorpo Santo e sua história confundem-se. 
Henrique, personagem de Pirandello na peça "Henrique IV", passa por uma enfermidade e toma para si o papel de louco. Há um momento em que percebe que não é mais possível livrar-se da máscara, ela obliterou a face do homem. Aceita-a definitivamente, reingressa no papel de louco, pois viver em um mundo instável é que é loucura.

O mesmo acontece a José Joaquim de Campos Leão. É como louco que o artista descobre o verdadeiro sentido da vida, que nada mais é que a contínua, "permanente mascarada, da qual somos os fantoches involuntários, quando, sem o sabermos, nos mascaramos daquilo que parecemos ser" (13).

Qorpo Santo, tal como Henrique, mascara-se daquilo que parece ser. Mas num ato voluntário, consciente, a fim de revelar o que verdadeiramente é, de maneira a driblar o caráter traiçoeiro da existência.

O artista desempenha o papel de louco contra a sua própria pessoa, e perdendo a distâcia do seu papel, o louco torna-se $o$ artista.

\section{NOTAS DE REFERÊNCIA}

1. Todas as citações das peças mencionadas referem-se à edição: Qorpo Santo. Teatro completo. org. CÉSAR, Guilhermino. Rio de Janeiro, SNT/FUNARTE, 1980

2. FOUCAULT, Michel. O mundo correcional. IN: _. História da loucura na idade Clássica. São Paulo, Perspectiva, 1978. p. 79

3. A interdição judicial. In: Qorpo Santo - Teatro completo. Org. Guilhermino César. Rio de Janeiro, SNT/FUNARTE, 1980. P.17

4. BRUNSTEIN, Robert._ O Teatro de protesto. Rio de Janeiro, Zahar, 1967. P. 418

5. ROSENFELD, Anatol. O fenômeno teatral. IN: Texto e contexto. 2a.ed. São Paulo, Perspectiva, 1973.

P.31

6. TOUCHARD, Pierre-Aimé. O Teatro e a Angústia dos homens. São Paulo, Livraria Duas Cidades, 1970.

P.201

7. GARCIA-ROZA, Luiz Alfredo. Freud e o inconsciente. Rio de Janeiro, Zahar, 1984. P.23

8. ROSENFELD. Op. Cit. p.31

9. LAING, R.D. O eu dividido. 4a.ed. Petrópolis, Vozes, 1982.P.190

10. LAING. Op. Cit. P.15

11. GARCIA_ROZA. Op. cit. p.30

12. MARCUSE, Herbert. Eros e Civilização. 8a.ed. Rio de Janeiro, Zahar, p. 135

13. BRUNSTEIN. Op. Cit. p. 328

\section{REFERÊNCIAS BIBLIOGRÁFICAS}

01.AGUIAR, Flávio. Os homens precários. Porto Alegre: INL/RS, 1975.

02.BRUNSTEIN, Robert. O teatro de protesto. Rio de Janeiro: Zahar, 1967.

03.FOUCAULT, Michel. História da loucura na Idade Clássica. São Paulo: Perspectiva, 1978. (Estudos,61) 04.GARCIA-ROZA, Luiz Alfredo. Freud e o incosciente. Rio de Janeiro: Zahar, 1984.

05.LAING, R.D. O Eu dividido. 4 ed. Petrópolis, Vozes, 1982

06.MARCUSE, Herbert. Eros e Civilização. 8 ed. Rio de Janeiro, Zahar, 1981

07.QORPO SANTO. Teatro Completo. ORG. CÉSAR, Guilhermino. Rio de Janeiro, SNT/FUNARTE, 1980.

(Clássicos do TeatroBrasileiro)

08.ROSENFELD, Anatol. Textos/Contexto. 2ำed. São Paulo, Perspectiva, 1973. (Debates,7).

09.SZASZ, Thomas S. Esquizofrenia. Rio de Janeiro, Zahar, 1978.

10.TOUCHARD, Pierre-Aimé. O Teatro e angústia dos homens. São Paulo, Livraria duas Cidades, 1970. 